Article

\title{
Degradation-Induced Actuation in Oxidation-Responsive Liquid Crystal Elastomers
}

\author{
Mahjabeen Javed, Seelay Tasmim, Mustafa K. Abdelrahman ${ }^{\circledR}$, Cedric P. Ambulo and \\ Taylor H. Ware *(D) \\ Department of Bioengineering, University of Texas at Dallas, Richardson, TX 75080, USA; \\ mxj180011@utdallas.edu (M.J.); Seelay.Tasmim@UTDallas.edu (S.T.); \\ Mustafa.Abdelrahman@utdallas.edu (M.K.A.); Cedric.Ambulo@utdallas.edu (C.P.A.) \\ * Correspondence: taylor.ware@utdallas.edu
}

Received: 3 May 2020; Accepted: 21 May 2020; Published: 25 May 2020

check for updates

\begin{abstract}
Stimuli-responsive materials that exhibit a mechanical response to specific biological conditions are of considerable interest for responsive, implantable medical devices. Herein, we report the synthesis, processing and characterization of oxidation-responsive liquid crystal elastomers that demonstrate programmable shape changes in response to reactive oxygen species. Direct ink writing (DIW) is used to fabricate Liquid Crystal Elastomers (LCEs) with programmed molecular orientation and anisotropic mechanical properties. LCE structures were immersed in different media (oxidative, basic and saline) at body temperature to measure in vitro degradation. Oxidation-sensitive hydrophobic thioether linkages transition to hydrophilic sulfoxide and sulfone groups. The introduction of these polar moieties brings about anisotropic swelling of the polymer network in an aqueous environment, inducing complex shape changes. 3D-printed uniaxial strips exhibit $8 \%$ contraction along the nematic director and $16 \%$ orthogonal expansion in oxidative media, while printed LCEs azimuthally deform into cones 19 times their original thickness. Ultimately, these LCEs degrade completely. In contrast, LCEs subjected to basic and saline solutions showed no apparent response. These oxidation-responsive LCEs with programmable shape changes may enable a wide range of applications in target specific drug delivery systems and other diagnostic and therapeutic tools.
\end{abstract}

Keywords: stimuli-responsive polymers; ROS-responsive polymers; liquid crystal elastomers

\section{Introduction}

Stimuli-responsive materials demonstrating sensitivity to physical or chemical stimuli have been investigated extensively in the field of biomedical sciences. These materials are characterized by dramatic physical changes demonstrating either reversible or irreversible transformations in shape [1], color [2], elastic modulus [3], or solubility [4], in response to small or moderate environmental variations. Temperature [5,6], light [7], solvents [8] and $\mathrm{pH}$ [9] are among the myriad of external stimuli that can be utilized to trigger responses in these environmentally sensitive materials. Of particular interest for medical devices are materials capable of responding to certain biological triggers like glucose [10], enzymes [11], salt concentration [12], and the redox balance [13]. Reactive oxygen species (ROS) have emerged as a useful in vivo chemical trigger with promising utility due to the strong correlation between their overproduction and a number of pathological disorders.

ROS are generated by all living organisms as a response to mitochondrial metabolism or by activated macrophages during foreign pathogen invasion [14]. They include chemically reactive radical and non-radical oxygen species such as the superoxide anion $\left(\mathrm{O}^{2-}\right)$, hydroxyl radical $\left(\mathrm{HO} \mathrm{O}^{\bullet}\right.$ and hydrogen peroxide $\left(\mathrm{H}_{2} \mathrm{O}_{2}\right)[15,16]$. Although the production of $\mathrm{ROS}$ is imperative for a multitude 
of innate physiological processes, overproduction can tilt the delicate balance between the free radical oxygen species and antioxidant activity in the cells. Such a disruption in the body's natural redox homeostasis can overwhelm the antioxidant system's ability to aptly detoxify these acute increases in oxidant concentrations $[17,18]$. This physiological phenomenon has been termed oxidative stress and has been linked to the pathophysiology of a number of ailments including diabetes [19], atherosclerotic disease [20], inflammatory disorders [21], and neurodegenerative disorders [22].

ROS-sensitive polymers are stimuli-responsive polymers that produce a desired change in the response to endogenously produced ROS. For example, polymers containing redox-responsive linkages, such as thioethers [23], seleniums [24], telluriums [25] and arylboronic esters [26], are capable of changes in solubility in a biologically relevant oxidative environment. Hubbell et al. first reported ROS-responsive polymeric vesicles, demonstrating the possibility of utilizing oxidation triggered nanocarriers for target specific drug delivery [27]. A significant amount of work has since been reported on polymers with oxidation-sensitive moieties demonstrating useful applications in arenas such as drug and gene delivery [13,28-30], tissue engineering [31] and a variety of diagnostic tools like biosensors [32] and imaging [33-35]. Despite the numerous reports on designing and investigating ROS-responsive materials of varying chemistries, programmable shape change to ROS has not been reported.

Liquid Crystal Elastomers (LCEs) are a class of shape-morphing polymers with the elasticity of elastomers and the long range orientational order of liquid crystals. LCEs are capable of large, reversible deformations in response to environmental triggers that induce reversible changes in order, such as heating. These materials show promise for applications in soft robotics [36,37], flexible implantable electronics [38], and artificial muscles [39,40]. The nematic phase in LCEs corresponds to a state of order where the liquid crystals' mesogens exhibit a one-dimensional orientational order, while the isotropic phase corresponds to a state of disorder. Processing LCE precursors in the nematic phase allows for the alignment of the nematic director to be controlled using a variety of techniques. Mechanical stretching [41], surface alignment [42], and the use of magnetic fields [43] have been previously used to prepare LCEs with programmed orientation. Subsequent photocrosslinking fixes the alignment of the mesogens in the nematic state, locking the materials with a predetermined molecular order. If the alignment is spatially patterned, the localized mechanical response in LCEs can exhibit both in-plane and out-of-plane mechanical deformation. Recently, direct ink writing (DIW) has emerged as a useful tool for encoding director alignment in LCE structures with 3D geometries [44-47]. As a photopolymerizable LCE ink is extruded, shear forces align the nematic phase along the designated print path. Photocuring these LCEs fixes the alignment pattern and results in stress-free actuation when triggered by an environmental stimulus. Even though heat [41,48], light [6,49] and solvents [8,50-52] have been studied extensively as actuation triggers, LCEs that respond to an endogenous biochemical signal have not been reported.

Herein, we report the synthesis and characterization of thioether based, ROS-responsive LCEs using a previously described two-stage, one-pot, thiol-ene reaction scheme. We report, for the first time, that these stimuli-responsive materials undergo programmable shape change when exposed to ROS (Figure 1b) [44]. These LCEs are capable of resisting diffusion of water molecules in the polymer network in aqueous environments. However, the incorporation of thioether linkages in the network renders these LCEs sensitive to oxidants, and the hydrophobic thioether groups are able to convert to polar sulfoxide and sulfone groups in response to the chemically reactive species. Oxidation of the LCEs results in the increased overall polarity of the system and, consequently, higher swelling in water. LCEs with programmed molecular orientations exhibit anisotropic swelling in such conditions, resulting in interesting mechanical changes. The eventual breakdown of the LCE polymer network due to polymer chain scission results in the fracture of the films into many small pieces. 


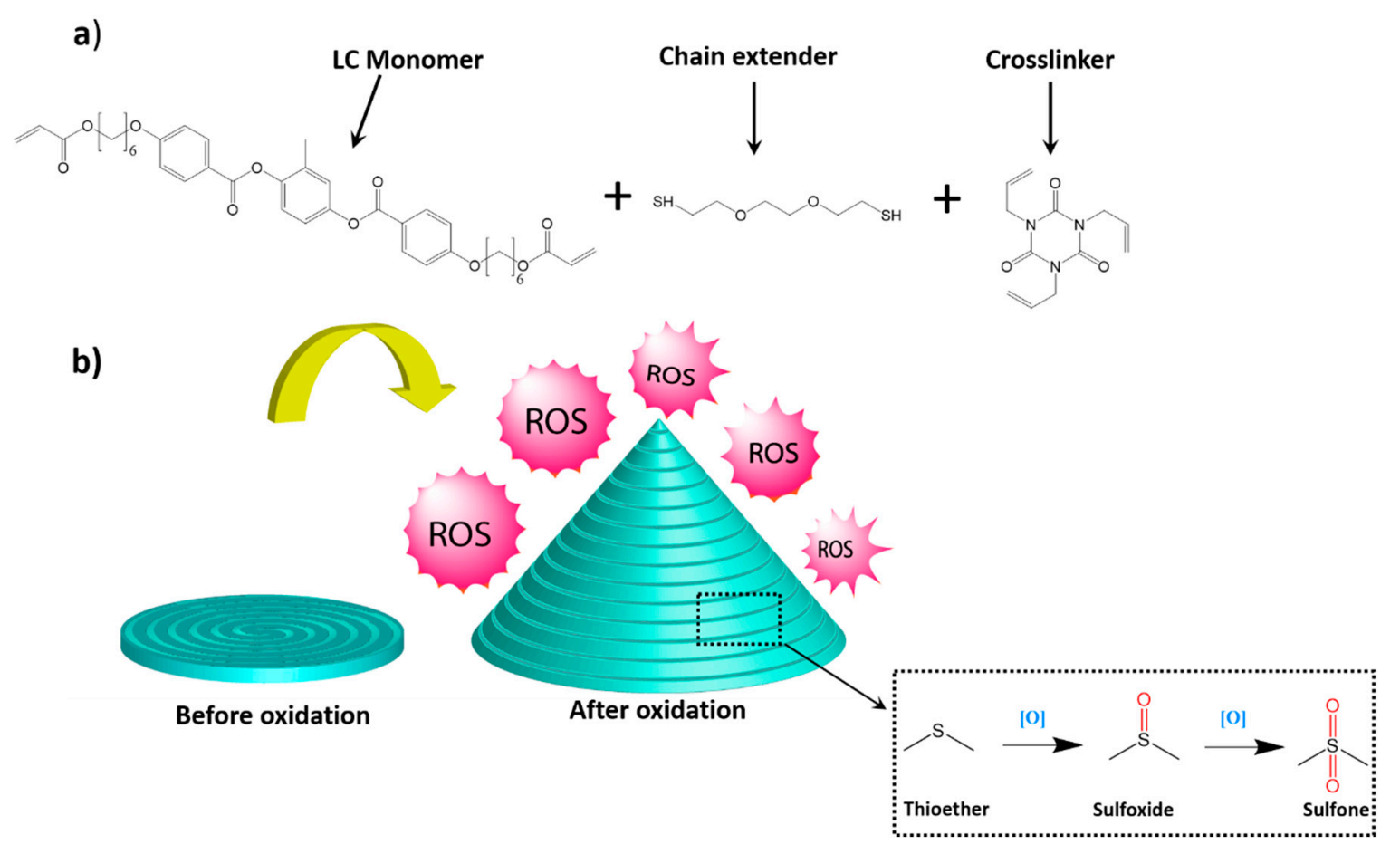

Figure 1. (a) Chemical structures of the liquid crystal (LC) monomer, (1,4-bis-[4-(6-acryloyloxhexyloxy) benzoyloxy]-2-methylbenzene (RM82)), thiol spacer, (2,2'-(ethylenedioxy) diethanethiol (EDDT)), and the vinyl crosslinker, (1,3,5-triallyl-1,3,5-triazine-2,4,6(1H,3H,5H)- trione (TATATO)), used to synthesize the oxidation-responsive polymers. (b) Schematic of a reactive oxtgen species (ROS)-sensitive Liquid Crystal Elastomer (LCE) disc with a patterned molecular orientation morphing from a flat configuration to a complex 3D structure in the presence of ROS.

\section{Materials and Methods}

\subsection{Materials}

The LC monomer (1,4-bis-[4-(6-acryloyloxhexyloxy)benzoyloxy]-2-methylbenzene (RM82)) was purchased from Wilshire Technologies, Inc. (Princeton, NJ, USA). The thiol spacer (2,2'-(ethylenedioxy) diethanethiol (EDDT)) and the vinyl crosslinker (1,3,5-triallyl-1,3,5-triazine-2,4,6(1H,3H,5H)-trione (TATATO)) were purchased from Sigma-Aldrich (St. Louis, MO, USA). The photoinitiator, Irgacure I-369, was donated by BASF Corporation (Ludwigshafen, RP, Germany). Triethylamine (TEA) was purchased from Sigma-Aldrich. Butylated hydroxytoluene (BHT) was purchased from Sigma-Aldrich. $30 \% \mathrm{H}_{2} \mathrm{O}_{2}$ was purchased from Fisher Scientific (Waltham, MA, USA) and diluted with RO water to obtain $20 \%$ and $3 \% \mathrm{H}_{2} \mathrm{O}_{2}$. Cobalt (II) Chloride (anhydrous) was purchased from Alfa Aesar (Haverhill, MA, USA). Sodium hydroxide pellets and phosphate-buffered saline tablets (pH 7.4) were purchased from Sigma-Aldrich.

\subsection{Direct Ink Writing (DIW)}

DIW was used to prepare 3D LCE structures with programmable shape change. LC monomer, RM82, was mixed with EDDT and TATATO in the molar ratio 0.8 acrylate:1.0 thiol:0.2 vinyl with $1 \mathrm{wt} \%$ of base catalyst TEA, $2 \mathrm{wt} \%$ of the radical scavenger BHT, and $1.5 \mathrm{wt} \%$ of the photoinitiator I- 369 . The mixture was left to oligomerize at $65^{\circ} \mathrm{C}$ for $3 \mathrm{~h}$. The thiol-terminated LCE oligomer ink was filled into KR-2 Extruder print head (Hyrel3D, Norcross, GA, USA) and printed using the 30M 3D printer (Hyrel3D, Norcross, GA, USA). Inks were printed at $38^{\circ} \mathrm{C}$ (ink reservoir temperature) and cross-linked via $365 \mathrm{~nm}$ LEDs located at the print heads with an intensity of $0.8 \mathrm{~mW} \mathrm{~cm}^{-2}$. Samples were post-cured 
under $365 \mathrm{~nm}$ UV light (OmniCure®LX400+, Lumen Dynamics, Waltham, MA, USA) with an intensity of $250 \mathrm{~mW} \mathrm{~cm}^{-2}$ for $15 \mathrm{~min}$.

\subsection{In Vitro Degradation}

LCE samples were tested for in vitro degradation in oxidative, hydrolytic and control media. $\mathrm{H}_{2} \mathrm{O}_{2}(20 \% w / v)$ was used with $0.1 \mathrm{M} \mathrm{CoCl}_{2}$ to catalyze the decomposition of the peroxide, as an accelerated oxidative treatment. The media was changed every other day. An accelerated oxidative solution was prepared by mixing $325 \mathrm{mg}$ of $\mathrm{CoCl}_{2}$ in $10 \mathrm{~mL}$ of $\mathrm{RO}$ water, while $50 \mathrm{~mL}$ of $30 \% \mathrm{w} / \mathrm{v}$ of $\mathrm{H}_{2} \mathrm{O}_{2}$ was poured in $15 \mathrm{~mL}$ of $\mathrm{RO}$ water, in a separate beaker. The diluted $\mathrm{H}_{2} \mathrm{O}_{2}$ was then poured in with the $\mathrm{CoCl}_{2}$ solution. To simulate real time degradation rates in a physiological environment, $3 \%$ $\mathrm{H}_{2} \mathrm{O}_{2}$ in water was used. This was prepared by diluting $10 \mathrm{~mL}$ of $30 \% \mathrm{H}_{2} \mathrm{O}_{2}$ with $90 \mathrm{~mL} \mathrm{RO}$ water. Phosphate-buffered saline (PBS) was used as the control and was prepared by dissolving one tablet in $200 \mathrm{~mL}$ of $\mathrm{RO}$ water, yielding a saline solution with $\mathrm{pH}$ of 7.4. A $0.1 \mathrm{M} \mathrm{NaOH}$ solution was used as the hydrolytic media and was prepared by mixing $800 \mathrm{mg}$ of $\mathrm{NaOH}$ pellets to $200 \mathrm{~mL}$ of $\mathrm{RO}$ water. Test specimens were submerged in their respective media in sealed vials and placed in an oven at $37^{\circ} \mathrm{C}$. To quantify mass changes, samples were removed from the solution every $12 \mathrm{~h}$, both sides were blotted dry with a Kim Wipe and mass was measured. Water uptake $(\boldsymbol{W A})$ by the specimens was calculated as follows:

$$
W A(\%)=\frac{m_{f}-m_{i}}{m_{i}} \times 100
$$

where $m_{f}$ is the final mass after the sample is patted dry and $m_{i}$ is the initial dry mass. Samples were carefully returned to the media after measurement.

\subsection{Differential Scanning Calorimetry (DSC)}

Differential scanning calorimetry (DSC) (TA Instruments) was performed to determine transition temperatures of the LCE before and after degradation. Polydomain films ( $1 \mathrm{~mm}$ thick) were exposed to the four media for 7 days, then vacuum dried at $65^{\circ} \mathrm{C}$ overnight. Samples with a mass of around $3 \mathrm{mg}$ were loaded into standard aluminum DSC pans, heated from room temperature to $150{ }^{\circ} \mathrm{C}$, cooled to $-40^{\circ} \mathrm{C}$, and then reheated to $150{ }^{\circ} \mathrm{C}$ at a rate of $\pm 10^{\circ} \mathrm{C} / \mathrm{min}$. Tg was determined using the second heating cycle. Three samples $(n=3)$ were tested.

\subsection{Dynamic Mechanical Analysis (DMA)}

Dynamic mechanical analysis (DMA) (TA instruments RSA-G2, New Castle, DE, USA) was used to determine the thermomechanical properties of the material before and after degradation. Polydomain LCE films were prepared by injecting LCE oligomer between two glass slides $(75 \mathrm{~mm} \times 51 \mathrm{~mm} \times$ $1.2 \mathrm{~mm}$, Electron Microscopy Sciences) separated by a $1 \mathrm{~mm}$ thick spacer and then photocrosslinking them using $365 \mathrm{~nm}$ UV light for 10 minutes, flipping the sample once. Rectangular test specimens with the dimensions of approximately $20 \mathrm{~mm} \times 5 \mathrm{~mm} \times 1 \mathrm{~mm}$ were prepared. Specimens were soaked in $20 \% \mathrm{H}_{2} \mathrm{O}_{2} / \mathrm{CoCl}_{2}, 3 \% \mathrm{H}_{2} \mathrm{O}_{2}, \mathrm{PBS}$ or $\mathrm{NaOH}$ at $37^{\circ} \mathrm{C}$ for 1,2 and 7 days and tested in immersion. Non-degraded LCE films were also tested. After being loaded, all samples were allowed to sit in PBS in the immersion chamber for around 15 minutes to equilibrate. Temperature sweep tests were done to analyze the Storage Modulus $\left(E^{\prime}\right)$ and damping coefficient (tan delta $\left.(\delta)\right)$ for samples before and after degradation at $0.2 \%$ dynamic strain and frequency of $1 \mathrm{~Hz}$ from 10 to $65^{\circ} \mathrm{C}$ at a rate of $2{ }^{\circ} \mathrm{C} \mathrm{min}{ }^{-1}$. Three samples $(\mathrm{n}=3)$ were tested.

\subsection{Shape Change}

Shape change in all samples was imaged by a Nikon digital single-lens reflex camera (DSLR). Dimensional changes were analyzed using ImageJ software (Fiji, 1.52p, NIH, WI, USA). 


\subsection{Fourier Transform Infrared Spectroscopy (FTIR)}

Fourier transform infrared spectroscopy (Agilent 660 FTIR, Agilent Technologies, Santa Clara, CA, USA ) was used in attenuated total reflection (ATR) mode to analyze oxidized films after drying. Three samples $(n=3)$ were tested. Before analyzing, samples were placed in $20 \% \mathrm{H}_{2} \mathrm{O}_{2} / \mathrm{CoCl}_{2}$ and $3 \% \mathrm{H}_{2} \mathrm{O}_{2}$ solutions at $37^{\circ} \mathrm{C}$ in sealed vials for 7 days. After a week, samples were removed from the oxidative media and dried overnight under vacuum at $65^{\circ} \mathrm{C}$ before testing. Non-degraded LCE films were also dried for consistency.

\subsection{Scanning Electron Microscopy (SEM)}

SEM (Zeiss Supra 40, Carl Zeiss AG, Oberkochen, BW, Germany) was used to analyze surface topography before and after oxidation. Samples to be imaged were placed in $20 \% \mathrm{H}_{2} \mathrm{O}_{2} / \mathrm{CoCl}_{2}$ and $3 \% \mathrm{H}_{2} \mathrm{O}_{2}$ at $37^{\circ} \mathrm{C}$ in sealed vials for 7 days. After a week, samples were removed from the oxidative media and dried overnight under vacuum at $65^{\circ} \mathrm{C}$. Dried samples were sputter-coated with $76 \AA$ of gold and palladium before being imaged.

\section{Results and Discussion}

The synthesis of a photopolymerizable LC ink was accomplished using a two-step thiol-ene reaction scheme [44]. Michael addition between a LC monomer with reactive acrylate end groups and a dithiol ensured a thiol-terminated oligomer with printable viscosity (Figure 1a). DIW enabled the spatial control of the nematic director in the direction of the print path. Photocrosslinking during printing induces crosslinks between the thiol-terminated oligomer and the vinyl crosslinker and preserves the alignment of the mesogens in the 3D LCE structure induced by the extrusion.

Printed specimens were placed in four types of media at $37^{\circ} \mathrm{C}$ for up to three days. Hydrogen peroxide with cobalt (II) chloride has been previously used to generate a high concentration of reactive oxygen species and simulate long term oxidation in a physiological environment in vitro [53,54]. For real time oxidation degradation rates, $3 \% \mathrm{H}_{2} \mathrm{O}_{2}$ in the absence of the metal ions was used as suggested by the ISO 10993-13 standard. Alternatively, to understand the behavior of the LCE in the absence of an oxidative environment, PBS was used as a negative control, and $0.1 \mathrm{M} \mathrm{NaOH}$ was used to simulate base-catalyzed hydrolytic degradation.

The oxidation of 3D LCE structures with a programmed molecular order leads to anisotropic shape change. Uniaxial strips were printed with print paths set along the short axis of the rectangular strips (Figure 2a). For quantitative assessment of anisotropic shape change, dimensional and mass changes in the strips were measured over time. Uniaxial strips showed a $21 \%$ increase in mass after being in $20 \% \mathrm{H}_{2} \mathrm{O}_{2}$ for just $12 \mathrm{~h}$, while samples immersed in $3 \% \mathrm{H}_{2} \mathrm{O}_{2}$ showed a $13 \%$ increase in mass (Figure 2b). A very slight mass change was observed in the strips that were in either control or basic solutions with $0.3 \%$ for PBS and $1 \%$ for $\mathrm{NaOH}$ over a period of $48 \mathrm{~h}$. These trends in the mass changes corresponded with the dimensional changes observed (Figure 2c,d). After being in $20 \% \mathrm{H}_{2} \mathrm{O}_{2}$ for $24 \mathrm{~h}$, uniaxial strips showed a decrease in width of $8 \%$ and a $16 \%$ elongation. After being in $3 \%$ $\mathrm{H}_{2} \mathrm{O}_{2}$ for $24 \mathrm{~h}$, strips similarly decreased in width (along the director) by $10 \%$. Strips also elongated by $9 \%$. The swelling of the polymer network is thought to result in the nematic to isotropic transition in the uniaxial strips. As a result, the strips contract along the short axis or parallel to the nematic director but elongate along the long axis or perpendicular to the nematic director. Similar macroscopic deformations through anisotropic swelling have been previously reported in LCEs responding to solvents, where contraction along the nematic director and expansion perpendicular to the director can be observed $[48,50,51]$. No dimensional changes were observed in the strips that were in either PBS or $\mathrm{NaOH}$ solution. Because the LCE with the thioether groups is inherently hydrophobic, the shape change exhibited by the LCE is not due to simple water uptake in an aqueous environment, but due to swelling induced by the presence of oxidants and the introduction of hydrophilic moieties in the polymer network. The solubility switch also leaves the LCEs highly susceptible to degradation, both 
oxidative and hydrolytic, leading to their fracture into many small pieces after a week of being in the oxidative media. Figure S1 (see Supplementary Materials) shows a uniaxial strip after 5 days of being in the media, which was the last day the samples could be reliably removed from the vial.

a)

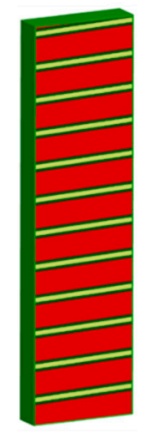

b)

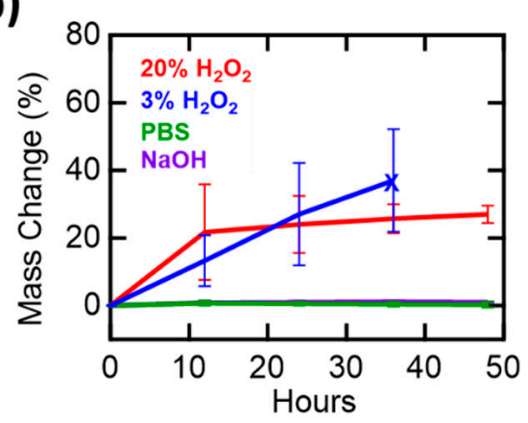

c)

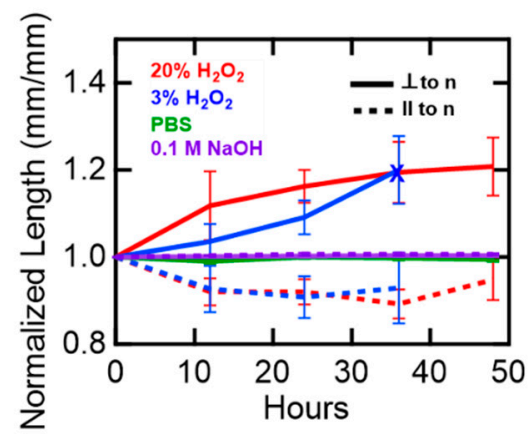

d)

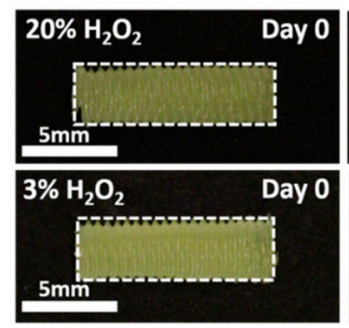

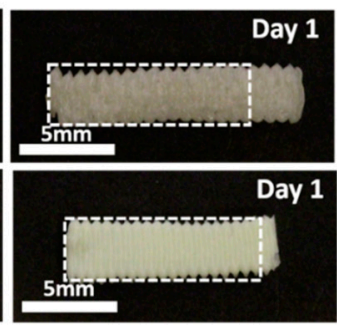

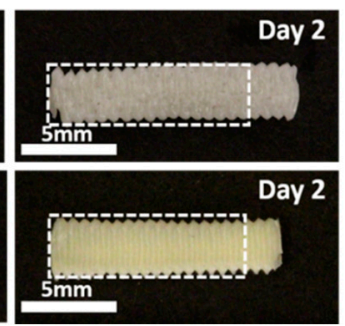

Figure 2. Shape change and mass change of 3D printed uniaxial strips. (a) Print schematic of single layer uniaxial strips. Print path is set to be along the short axis of the rectangular strips resulting in nematic director parallel to the short axis and perpendicular to the long axis. (b) Mass change (\%) as a function of time for uniaxial strips in all four media. Test specimens in oxidative media swell significantly while those in PBS and $\mathrm{NaOH}$ solution showed approximately no change. (c) Normalized length $(\mathrm{mm} / \mathrm{mm})$ for uniaxial strips, parallel and perpendicular to the nematic director (n), as a function for time for strips in all four media. Films in oxidative media demonstrate anisotropic swelling with contraction along the short axis and elongation along the long axis. (d) Shape change of uniaxial strips before and after oxidation in $20 \% \mathrm{H}_{2} \mathrm{O}_{2}$ and $3 \% \mathrm{H}_{2} \mathrm{O}_{2}$.

The effects of degradation can be clearly observed on the viscoelastic properties of the LCE. To measure these properties, DMA was performed on polydomain films in water after removal from the degradation solution. After oxidation in $20 \% \mathrm{H}_{2} \mathrm{O}_{2}$ for a day, the LCE demonstrates a drop in the rubbery modulus ( $\mathrm{E}^{\prime}$ ) from 3.4 MPa to $1.7 \mathrm{MPa}$ at $10^{\circ} \mathrm{C}$ (Figure 3a, Figure S2a). This temperature is well above the glass transition temperature for these films, which is around $-25^{\circ} \mathrm{C}$. After oxidation, samples also exhibited a lack of peak in tan delta which could be observed in LCEs at around $30^{\circ} \mathrm{C}$, prior to oxidation (Figure 3b, Figure S2b,d,f). This peak likely corresponds to a smectic to nematic mesophase transition [44], and its disappearance demonstrates the order disruption induced by the degradation and swelling. On Day 7, the rubbery modulus dropped to $0.8 \mathrm{MPa}$ at $10^{\circ} \mathrm{C}$ (Figure 3a, Figure S2e). Tan delta is highest for films on Day 7, which suggests an increase in viscoelastic behavior and further signifies the degradation of the films on Day 7 (Figure 3b, Figure S2f). Films in $3 \% \mathrm{H}_{2} \mathrm{O}_{2}$ exhibited similar trends of oxidation and degradation but at a slower rate compared to those in $20 \% \mathrm{H}_{2} \mathrm{O}_{2}$, with significant degradation only taking place on Day 7 (Figure 3c,d, Figure S3). Degradation was again characterized by a drop in rubbery modulus, increase in tan delta and a gradual disappearance of the tan delta peak. Alternatively, films that were subjected to either PBS or $\mathrm{NaOH}$ solution showed very little change in mass or thermomechanical properties over the same period of time (Figure S4a-d). We note that samples for dynamic mechanical analysis were polydomain samples and were thicker than the aligned films discussed in Figure 2. The degradation behavior of these thicker materials followed 
similar trends to the thinner materials but they occurred over a longer time period. (Figure S4e). These thermomechanical data suggest that oxidative conditions lead to the disordering of the polymer network and a reduction in crosslinking that is characteristic of degradation.
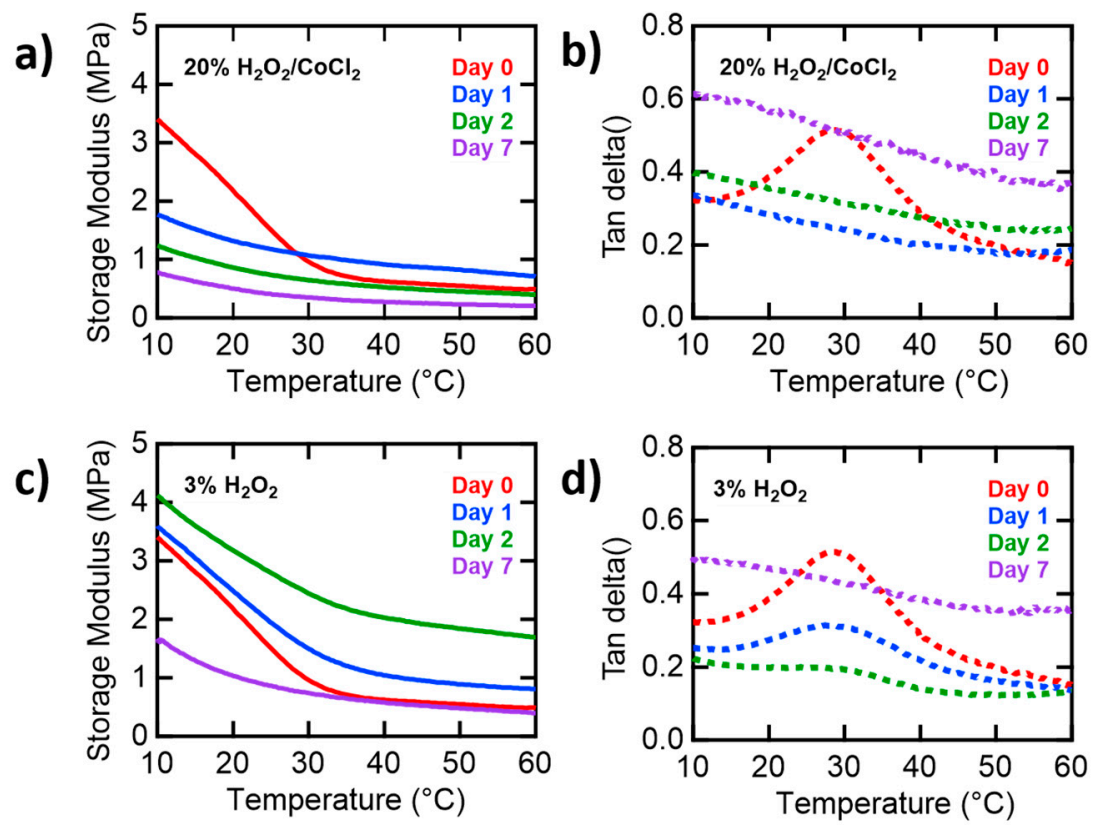

Figure 3. Effects of degradation on the viscoelastic properties of LCEs. (a) Storage Modulus (E') as a function of temperature, comparing non-degraded films with films oxidized for 1, 2 and 7 days in $20 \%$ $\mathrm{H}_{2} \mathrm{O}_{2} / \mathrm{CoCl}_{2}$ at $37^{\circ} \mathrm{C}$. (b) Respective tan delta curve as a function of temperature. (c) Storage Modulus (E') as a function of time for LCE films after exposure to $3 \% \mathrm{H}_{2} \mathrm{O}_{2}$ at $37{ }^{\circ} \mathrm{C}$ for 1,2 and 7 days and non-degraded films. (d) Respective curve of tan delta as a function of temperature.

The degradation of the LCEs in oxidative media is characterized by the formation of sulfoxide and sulfone functional groups from the thioether groups present after synthesis. All test specimens subjected to oxidative environments showed an increase in glass transition temperatures $\left(\mathrm{T}_{\mathrm{g}}\right)$ as well as appearance of a mesophase transition (Figure $4 \mathrm{a}$ ) after drying. After processing, the $\mathrm{T}_{\mathrm{g}}$ of the LCE is $-25^{\circ} \mathrm{C}$ and the nematic-isotropic transition is difficult to detect, as expected in elastomers crosslinked in the nematic phase. Films oxidized in $20 \% \mathrm{H}_{2} \mathrm{O}_{2}$ and then dried showed a $\mathrm{T}_{\mathrm{g}}$ at $8{ }^{\circ} \mathrm{C}$. This increased $\mathrm{T}_{\mathrm{g}}$ is expected as the flexible thioether groups are converted to more rigid and polar sulfoxide and sulfones [55]. The oxidized and dried materials also exhibit a low enthalpy (3.3 J/g) endothermic transition at $87^{\circ} \mathrm{C}$ on heating. The low enthalpy $(3.3 \mathrm{~J} / \mathrm{g})$ and low hysteresis $\left(4^{\circ} \mathrm{C}\right)$, as determined from comparing the first cooling cycle (Figure $4 \mathrm{~b}$ ) with the second heating cycle, indicates that this endothermic transition is likely a mesophase transition from nematic-isotropic [43,54]. The appearance of this mesophase transition suggests that regions of the film are no longer crosslinked and thus show typical mesophase-isotropic phase transitions on heating. Similarly, films in $3 \% \mathrm{H}_{2} \mathrm{O}_{2}$ also exhibited an increased $\mathrm{T}_{\mathrm{g}}\left(-9^{\circ} \mathrm{C}\right)$ and a mesophase transition at $94^{\circ} \mathrm{C}$ after degradation and drying. Films that were in control solutions showed no change in transitions temperature compared to the untreated LCE specimens. Fourier transform infrared spectroscopy (FTIR) further confirmed the presence of polar groups in the network after oxidation (Figure 4c). The appearance of sulfoxide absorption peaks are observed in oxidized samples at $1037 \mathrm{~cm}^{-1}$ and sulfone peaks at $1276 \mathrm{~cm}^{-1}$ and $1315 \mathrm{~cm}^{-1}[55,56]$. SEM analysis of films before and after oxidation showed effects of oxidation on surface topography. Physical degradation could be seen on the surface of samples that were oxidized in $20 \%$ and $3 \% \mathrm{H}_{2} \mathrm{O}_{2}$ (Figure $4 \mathrm{~d}, \mathrm{e}$ ). The oxidized sample had a rough, uneven surface, while the surface of the unoxidized sample was relatively smooth (Figure 4f). 

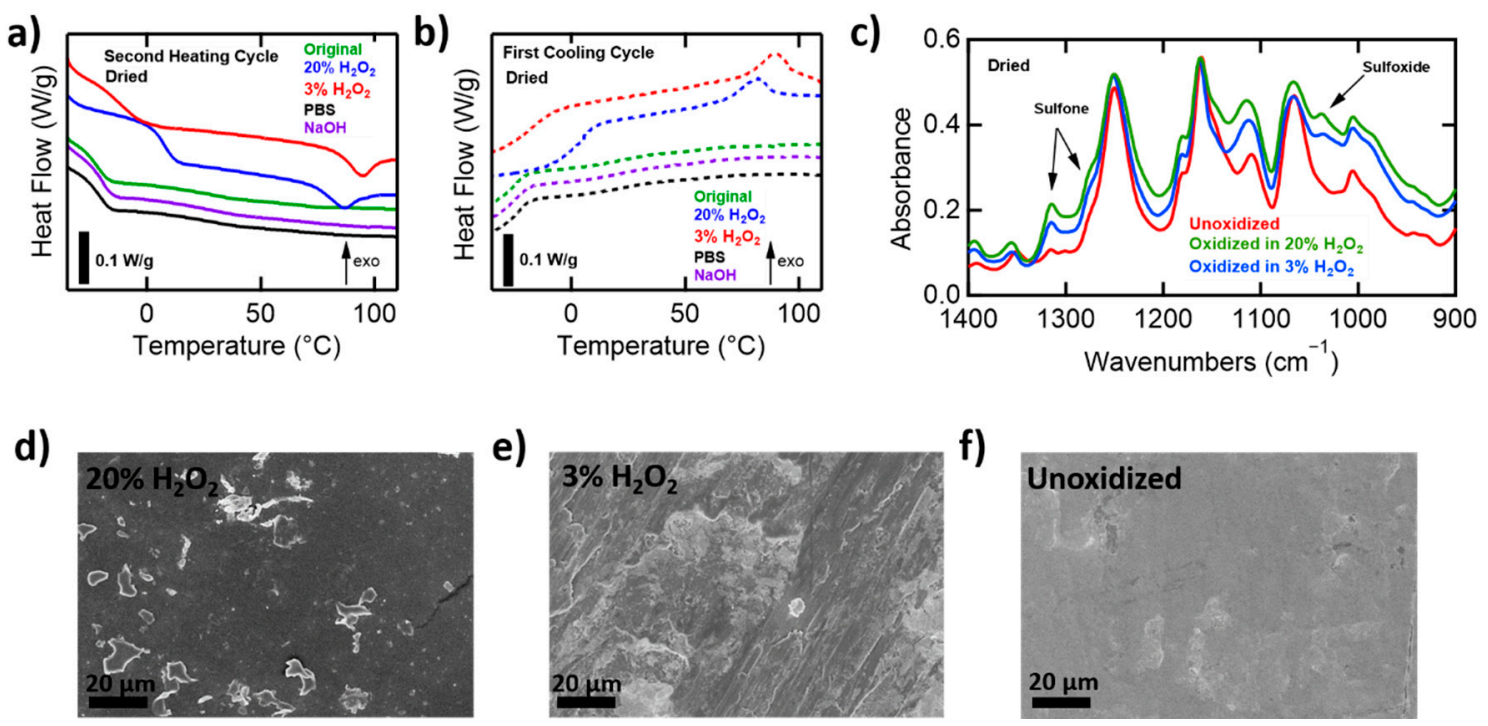

Figure 4. Material characterization of degraded LCE films after drying. (a) Differential scanning calorimetry (DSC) plot of second heating cycle. Heat flow as a function of temperature for $1 \mathrm{~mm}$ thick films after exposure to all media for 7 days and then dried compared to untreated LCEs. (b) DSC plot of first cooling cycle. (c) FTIR ATR results showing the effect of oxidation on $1 \mathrm{~mm}$ thick dried LCEs after exposure to oxidative media for 7 days. SEM images compare surface topographies of oxidized LCEs to unoxidized LCEs. (d) Effects of oxidation in $20 \% \mathrm{H}_{2} \mathrm{O}_{2}$. (e) Effects of oxidation in $3 \% \mathrm{H}_{2} \mathrm{O}_{2}$. (f) Unoxidized LCE.

LCEs with spatially varied print paths undergo complex 3D deformations in response to ROS. Approximately $400 \mu \mathrm{m}$ thick LCE discs were printed with the print path directed to be along an azimuthal alignment pattern (Figure 5a). Modes et al. [57] first proposed the use of azimuthal +1 disclination in liquid crystal polymer networks to create flat films that morph into cones, and it has since been demonstrated in aligned LCEs $[45,48,58,59]$. After being immersed in oxidative media, flat LCEs printed with an azimuthal print path clearly exhibit ROS sensitivity and actuated into cones (Figure 5 b). Discs in $20 \% \mathrm{H}_{2} \mathrm{O}_{2}$ exhibited a sharp increase in cone height which reached 19 times the original film thickness after the first $24 \mathrm{~h}$ and stayed relatively constant as time progressed (Figure $5 \mathrm{c}$ ). Discs in $3 \% \mathrm{H}_{2} \mathrm{O}_{2}$ demonstrated similar behavior, where cone height reaches 13 times the original film thickness after the first $24 \mathrm{~h}$. This height continued to increase over time and reached approximately 19 times the original film thickness after $48 \mathrm{~h}$ of being in the medium. It is worth noting that these shape changes are irreversible. LCEs do not go back to their original shape after they are removed from the oxidative media or after being brought down to room temperature. Alternatively, LCEs in the $\mathrm{PBS}$ and $\mathrm{NaOH}$ solutions, both, showed only a very slight increase in cone height when compared to the oxidative environments. 3D-printed LCE films of the same thickness showed a very slight mass change in control and basic solutions (Figure 2b). As the azimuthal alignment pattern amplifies mechanical deformation, we believe this relatively small displacement in the cone height arises from a slight swelling of the samples.

LCEs with director profiles that change through the thickness can be printed to create ROS-responsive materials that bend and twist. Bilayer strips were printed with the print path of the top and bottom layer directed to be $\pm 45^{\circ}$ to the long axis of the film (Figure $5 \mathrm{~d}$ ). The films morph from a flat to twisted geometry upon swelling in oxidative media (Figure 5e). Films in $20 \%$ $\mathrm{H}_{2} \mathrm{O}_{2}$ formed a helix after being in an oxidative environment for the first $12 \mathrm{~h}$, exhibiting an average of $33^{\circ} \mathrm{mm}^{-1}$ of twist per length (Figure $5 \mathrm{f}$ ). These twisted films continued swelling and after $36 \mathrm{~h}$ demonstrated an increase in pitch and a decrease in the number of twists. Films in $3 \% \mathrm{H}_{2} \mathrm{O}_{2}$ twisted to form helicoids instead. These increased the number of turns over a period of $36 \mathrm{~h}$, reaching an average of $31^{\circ} \mathrm{mm}^{-1}$ twists per length. Even though the different nature of twisting was unexpected, 
nematic elastomer films have previously been shown to deform into helicoids or spiral ribbons upon heating depending on the aspect ratio and elastic modulus [60]. The different rates of change in elastic modulus and shape change in the two conditions may lead to these distinct behaviors.

a)

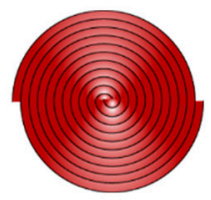

d)

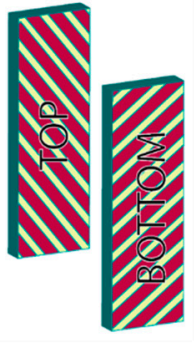

b)
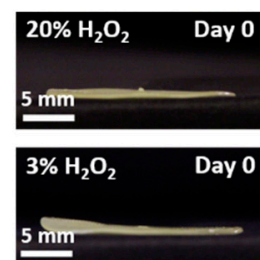

e)

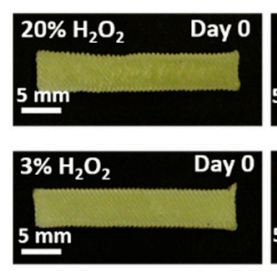

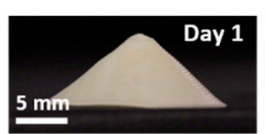

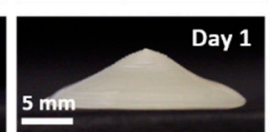

$5 \mathrm{~mm}$

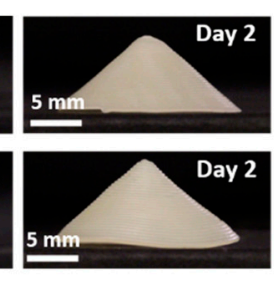

$5 \mathrm{~mm}$

f)
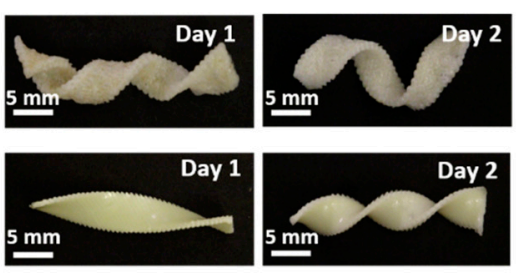

c)
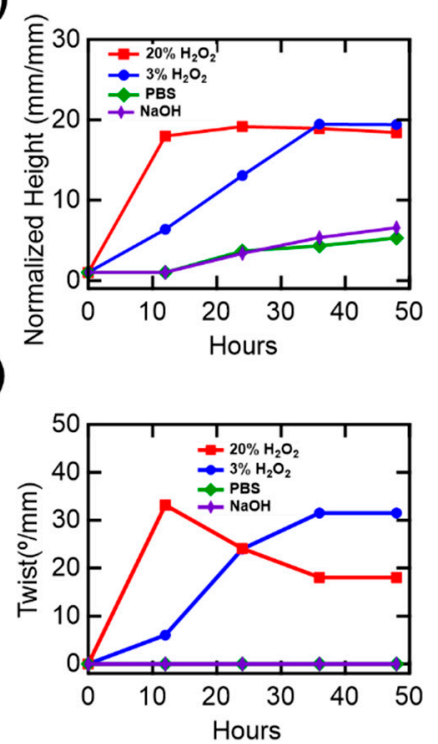

Figure 5. Shape change of 3D printed nonuniaxial structures. (a) Print path schematic of a disc with an azimuthal alignment pattern. (b) Side view images of 3D printed discs before and after oxidation in $20 \%$ $\mathrm{H}_{2} \mathrm{O}_{2}$ and $3 \% \mathrm{H}_{2} \mathrm{O}_{2}$. LCEs swell anisotropically and morph from a flat to conical shape. (c) Normalized cone height as a function of time after exposure to all media. (d) Print path schematic of bilayer LCE strips with the print path of opposing layers directed to be $\pm 45^{\circ}$ to the long axis of the film. (e) Flat rectangular bilayers morph into spiral ribbons or helicoids after oxidation. (f) Number of twists as a function of time demonstrating effect of media on bilayer.

\section{Conclusions}

Thiol-ene chemistry was utilized to synthesize LCE structures with ROS-sensitive thioether linkages. When in a biologically relevant oxidative environment, LCEs are triggered to undergo a transition from hydrophobic to hydrophilic states and swell anisotropically. LCEs with predetermined orientations exhibit macroscopic dimensional changes and morph from 2D to 3D geometries. This degradation-induced actuation leads to LCEs that fracture into many small constituents. Thermomechanical characterization of oxidized LCEs indicates that oxidation induces a loss in order and a reduction in the rubbery modulus. LCEs that respond to an endogenous biochemical signal can be availed for applications like smart devices for drug delivery and biosensing.

Supplementary Materials: The following are available online at http://www.mdpi.com/2073-4352/10/5/420/s1, Figure S1: Uniaxial strip after being in an oxidative media for 5 days. Figure S2: Effects of degradation on the viscoelastic properties of LCEs in control and hydrolytic solutions. Figure S3: DMA replicates for samples after degrading in $20 \% \mathrm{H}_{2} \mathrm{O}_{2}$ for 1,2 , and 7 day $(\mathrm{s})(\mathrm{n}=3)$. Figure $\mathrm{S} 4$ : DMA replicates for samples after degrading in $3 \%$ $\mathrm{H}_{2} \mathrm{O}_{2}$ for 1,2 , and 7 day(s) $(\mathrm{n}=3)$.

Author Contributions: Conceptualization, M.J. and T.H.W.; data curation, M.J.; formal analysis, M.J. and T.H.W.; funding acquisition, T.H.W.; Investigation, M.J., S.T. and M.K.A.; methodology, M.J. and T.H.W.; project administration, T.H.W.; resources, T.H.W.; software, S.T. and C.P.A.; supervision, T.H.W.; validation, M.J., S.T. and C.P.A.; visualization, M.J.; writing—original draft, M.J. and T.H.W.; writing-review \& editing, M.J., S.T., M.K.A., C.P.A. and T.H.W. All authors have read and agreed to the published version of the manuscript.

Funding: This material is partially based upon work supported by the National Science Foundation under Grant No. 1752846. Research reported in this publication was partially supported by the National Institute of Biomedical Imaging And Bioengineering of the National Institutes of Health under Award Number R21EB028547. The content is solely the responsibility of the authors and does not necessarily represent the official views of the National Institutes of Health. 
Acknowledgments: We thank Christopher Owen Blanchard for his assistance with the polymer synthesis and mass measurements.

Conflicts of Interest: The authors declare no conflict of interest.

\section{References}

1. Chung, T.; Romo-Uribe, A.; Mather, P.T. Two-way reversible shape memory in a semicrystalline network. Macromolecules 2008, 41, 184-192. [CrossRef]

2. Stumpel, J.E.; Broer, D.J.; Schenning, A.P.H.J. Water-responsive dual-coloured photonic polymer coatings based on cholesteric liquid crystals. RSC Adv. 2015, 5, 94650-94653. [CrossRef]

3. Norioka, C.; Okita, K.; Mukada, M.; Kawamura, A.; Miyata, T. Biomolecularly stimuli-responsive tetra-poly (ethylene glycol) that undergoes sol-gel transition in response to a target biomolecule. Polym. Chem. 2017, 8, 6378-6385. [CrossRef]

4. Xiao, C.; Ding, J.; Ma, L.; Yang, C.; Zhuang, X.; Chen, X. Synthesis of thermal and oxidation dual responsive polymers for reactive oxygen species (ROS)-triggered drug release. Polym. Chem. 2015, 6, 738-747. [CrossRef]

5. Haba, Y.; Kojima, C.; Harada, A.; Kono, K. Control of temperature-sensitive properties of poly(amidoamine) dendrimers using peripheral modification with various alkylamide groups. Macromolecules 2006, 39, 7451-7453. [CrossRef]

6. White, T.J.; Broer, D.J. Programmable and adaptive mechanics with liquid crystal polymer networks and elastomers. Nat. Mater. 2015, 14, 1087-1098. [CrossRef] [PubMed]

7. Camacho-Lopez, M.; Finkelmann, H.; Palffy-Muhoray, P.; Shelley, M. Fast liquid-crystal elastomer swims into the dark. Nat. Mater. 2004, 3, 307-310. [CrossRef] [PubMed]

8. Urayama, K.; Mashita, R.; Arai, Y.O.; Takigawa, T. Swelling and shrinking dynamics of nematic elastomers having global director orientation. Macromolecules 2006, 39, 8511-8516. [CrossRef]

9. Liu, F.; Urban, M.W. Dual temperature and $\mathrm{pH}$ responsiveness of poly(2-(N,N-dimethylamino)ethyl methacrylate-co-n-butyl acrylate) colloidal dispersions and their films. Macromolecules 2008, 41, 6531-6539. [CrossRef]

10. Kataoka, K.; Miyazaki, H.; Bunya, M.; Okano, T.; Sakurai, Y. Totally synthetic polymer gels responding to external glucose concentration: Their preparation and application to on-off regulation of insulin release. J. Am. Chem. Soc. 1998, 120, 12694-12695. [CrossRef]

11. Thornton, P.D.; Mart, R.J.; Ulijn, R.V. Enzyme-responsive polymer hydrogel particles for controlled release. Adv. Mater. 2007, 19, 1252-1256. [CrossRef]

12. Maji, S.; Cesur, B.; Zhang, Z.; de Geest, B.G.; Hoogenboom, R. Poly(N-isopropylacrylamide) coated gold nanoparticles as colourimetric temperature and salt sensors. Polym. Chem. 2016, 7, 1705-1710. [CrossRef]

13. Cheng, Y.; Jiao, X.; Xu, T.; Wang, W.; Cao, Y.; Wen, Y.; Zhang, X. Free-Blockage Mesoporous Anticancer Nanoparticles Based on ROS-Responsive Wetting Behavior of Nanopores. Small 2017, 13, 1-9. [CrossRef] [PubMed]

14. Ray, P.D.; Huang, B.W.; Tsuji, Y. Reactive oxygen species (ROS) homeostasis and redox regulation in cellular signaling. Cell. Signal. 2012, 24, 981-990. [CrossRef] [PubMed]

15. Mackay, C.E.; Knock, G.A. Control of vascular smooth muscle function by Src-family kinases and reactive oxygen species in health and disease. J. Physiol. 2015, 593, 3815-3828. [CrossRef] [PubMed]

16. Finkel, T. Signal transduction by reactive oxygen species. J. Cell Biol. 2011, 194, 7-15. [CrossRef]

17. Vo, C.D.; Kilcher, G.; Tirelli, N. Polymers and sulfur: What are organic polysulfides good for? Preparative strategies and biological applications. Macromol. Rapid Commun. 2009, 30, 299-315. [CrossRef]

18. Joshi-Barr, S.; De Gracia Lux, C.; Mahmoud, E.; Almutairi, A. Exploiting oxidative microenvironments in the body as triggers for drug delivery systems. Antioxid. Redox Signal. 2014, 21, 730-754. [CrossRef]

19. Rains, J.L.; Jain, S.K. Oxidative stress, insulin signaling, and diabetes. Free Radic. Biol. Med. 2011, 50, 567-575. [CrossRef]

20. Keaney, J.F.; Vita, J.A. Atherosclerosis, oxidative stress, and antioxidant protection in endothelium-derived relaxing factor action. Prog. Cardiovasc. Dis. 1995, 38, 129-154. [CrossRef]

21. Reuter, S.; Gupta, S.C.; Chaturvedi, M.M.; Aggarwal, B.B. Oxidative stress, inflammation, and cancer. Free Radic. Biol. Med. 2011, 49, 1603-1616. [CrossRef] [PubMed] 
22. Tönnies, E.; Trushina, E. Oxidative Stress, Synaptic Dysfunction, and Alzheimer's Disease. J. Alzheimer's Dis. 2017, 57, 1105-1121. [CrossRef] [PubMed]

23. Hu, P.; Tirelli, N. Scavenging ROS: Superoxide dismutase/catalase mimetics by the use of an oxidation-sensitive nanocarrier/enzyme conjugate. Bioconjug. Chem. 2012, 23, 438-449. [CrossRef] [PubMed]

24. Ma, N.; Li, Y.; Ren, H.; Xu, H.; Li, Z.; Zhang, X. Selenium-containing block copolymers and their oxidation-responsive aggregates. Polym. Chem. 2010, 1, 1609-1614. [CrossRef]

25. Wang, L.; Fan, F.; Cao, W.; Xu, H. Ultrasensitive ROS-Responsive Coassemblies of Tellurium-Containing Molecules and Phospholipids. ACS Appl. Mater. Interfaces 2015, 7, 16054-16060. [CrossRef]

26. Kim, E.J.; Bhuniya, S.; Lee, H. An activatable prodrug for the treatment of metastatic tumors. J. Am. Chem. Soc. 2014, 136, 13888-13894. [CrossRef]

27. Napoli, A.; Valentini, M.; Tirelli, N.; Müller, M.; Hubbell, J.A. Oxidation-responsive polymeric vesicles. Nat. Mater. 2004, 3, 183-189. [CrossRef] [PubMed]

28. Yoo, J.; Rejinold, N.S.; Lee, D.Y.; Jon, S.; Kim, Y.C. Protease-activatable cell-penetrating peptide possessing ROS-triggered phase transition for enhanced cancer therapy. J. Control. Release 2017, 264, 89-101. [CrossRef] [PubMed]

29. Yuan, Y.; Zhang, C.J.; Liu, B. A Photoactivatable AIE Polymer for Light-Controlled Gene Delivery: Concurrent Endo/Lysosomal Escape and DNA Unpacking. Angew. Chem. Int. Ed. 2015, 54, 11419-11423. [CrossRef] [PubMed]

30. Shim, M.S.; Xia, Y. A Reactive Oxygen Species (ROS)-Responsive Polymer for Safe, Efficient, and Targeted Gene Delivery in Cancer Cells. Angew. Chem. 2014, 23, 1-7. [CrossRef]

31. Lee, S.H.; Boire, T.C.; Lee, J.B.; Gupta, M.K.; Zachman, A.L.; Rath, R.; Sung, H. ROS-cleavable proline oligomer crosslinking of polycaprolactone for pro-angiogenic host response. J. Mater. Chem. B 2014, 2, 7109-7113. [CrossRef] [PubMed]

32. Zhou, L.; Luo, F.; Chi, W.; Tang, Y.; Liu, X.; Lin, Q. Activatable selenium-containing fluorescent apoptotic agent for biosensing and tracing cancer cell apoptosis. Sens. Actuators B Chem. 2020, 311, 127915. [CrossRef]

33. Gomes, A.; Fernandes, E.; Lima, J.L.F.C. Fluorescence probes used for detection of reactive oxygen species. J. Biochem. Biophys. Methods 2005, 65, 45-80. [CrossRef] [PubMed]

34. Lee, D.; Bae, S.; Ke, Q.; Lee, J.; Song, B.; Karumanchi, S.A.; Khang, G.; Choi, H.S.; Kang, P.M. Hydrogen peroxide-responsive copolyoxalate nanoparticles for detection and therapy of ischemia-reperfusion injury. J. Control. Release 2013, 172, 1102-1110. [CrossRef] [PubMed]

35. Li, W.; Khan, M.; Lin, L.; Zhang, Q.; Feng, S.; Wu, Z.; Lin, J. Monitoring $\mathrm{H}_{2} \mathrm{O}_{2}$ on the Surface of Single Cells with Liquid Crystal Elastomer Microspheres. Angew. Chem. 2020. [CrossRef]

36. Zhang, Y.; Wang, Z.; Yang, Y.; Chen, Q.; Qian, X.; Wu, Y.; Liang, H. Seamless multimaterial 3D liquid-crystalline elastomer actuators for next-generation entirely soft robots. Sci. Adv. 2020, 6. [CrossRef] [PubMed]

37. He, Q.; Wang, Z.; Wang, Y.; Minori, A.; Tolley, M.T.; Cai, S. Electrically controlled liquid crystal elastomer-based soft tubular actuator with multimodal actuation. Sci. Adv. 2019, 5, 1-8. [CrossRef]

38. Rihani, R.T.; Kim, H.; Black, B.J. Liquid crystal elastomer-based microelectrode array for in vitro neuronal recordings. Micromachines 2018, 9, 416. [CrossRef]

39. Li, M.H.; Keller, P.; Antonietti, M.; Lacey, D.; Meyer, R.B. Artificial muscles based on liquid crystal elastomers. Philos. Trans. R. Soc. A Math. Phys. Eng. Sci. 2006, 364, 2763-2777. [CrossRef]

40. Thomsen, D.L.; Keller, P.; Naciri, J.; Pink, R.; Jeon, H.; Shenoy, D.; Ratna, B.R. Liquid crystal elastomers with mechanical properties of a muscle. Macromolecules 2001, 34, 5868-5875. [CrossRef]

41. Kiipfec, J.; Finkelrnann, H. Nematic liquid single crystal elastomers. Makromol. Chem. 1991, 726, 717-726.

42. Guo, Y.; Jiang, M.; Peng, C.; Sun, K. High-Resolution and High-Throughput Plasmonic Photopatterning of Complex Molecular Orientations in Liquid Crystals. Adv. Mater. 2016, 28, 2353-2358. [CrossRef] [PubMed]

43. Buguin, A.; Li, M.H.; Silberzan, P.; Ladoux, B.; Keller, P. Micro-actuators: When artificial muscles made of nematic liquid crystal elastomers meet soft lithography. J. Am. Chem. Soc. 2006, 128, 1088-1089. [CrossRef] [PubMed]

44. Saed, M.O.; Ambulo, C.P. Molecularly-Engineered, 4D-Printed Liquid Crystal Elastomer Actuators. Adv. Funct. Mater. 2019, 29, 1-9. [CrossRef]

45. Ambulo, C.P.; Burroughs, J.J.; Boothby, J.M.; Kim, H.; Shankar, M.R.; Ware, T.H. Four-dimensional Printing of Liquid Crystal Elastomers. ACS Appl. Mater. Interfaces 2017, 9, 37332-37339. [CrossRef] 
46. López-Valdeolivas, M.; Liu, D.; Broer, D.J.; Sánchez-Somolinos, C. 4D Printed Actuators with Soft-Robotic Functions. Macromol. Rapid Commun. 2018, 39, 3-9. [CrossRef]

47. Kotikian, A.; Truby, R.L.; Boley, J.W.; White, T.J.; Lewis, J.A. 3D Printing of Liquid Crystal Elastomeric Actuators with Spatially Programed Nematic Order. Adv. Mater. 2018, 30, 1-6. [CrossRef]

48. Ware, T.H.; McConney, M.E.; Wie, J.J.; Tondiglia, V.P.; White, T.J. Voxelated liquid crystal elastomers. Science 2015, 347, 982-984. [CrossRef]

49. Yamada, M.; Kondo, M.; Miyasato, R. Photomobile polymer materials-Various three-dimensional movements. J. Mater. Chem. 2009, 19, 60-62. [CrossRef]

50. Boothby, J.M.; Kim, H.; Ware, T.H. Shape changes in chemoresponsive liquid crystal elastomers. Sens. Actuators B Chem. 2017, 240, 511-518. [CrossRef]

51. Urayama, K.; Arai, Y.O.; Takigawa, T. Anisotropic swelling and phase behavior of monodomain nematic networks in nematogenic solvents. Macromolecules 2005, 38, 5721-5728. [CrossRef]

52. Urayama, K.; Okuno, Y.; Kohjiya, S. Volume transition of liquid crystalline gels in isotropic solvents. Macromolecules 2003, 36, 6229-6234. [CrossRef]

53. Weems, A.C.; Wacker, K.T.; Carrow, J.K.; Boyle, A.J.; Maitland, D.J. Shape memory polyurethanes with oxidation-induced degradation: In vivo and in vitro correlations for endovascular material applications. Acta Biomater. 2017, 59, 33-44. [CrossRef] [PubMed]

54. Dempsey, D.K.; Carranza, C.; Chawla, C.P. Comparative analysis of in vitro oxidative degradation of poly(carbonate urethanes) for biostability screening. J. Biomed. Mater. Res. Part A 2014, 102, 3649-3665. [CrossRef] [PubMed]

55. Podgórski, M.; Wang, C.; Yuan, Y.; Konetski, D.; Smalyukh, I.; Bowman, C.N. Pristine Polysulfone Networks as a Class of Polysulfide-Derived High-Performance Functional Materials. Chem. Mater. 2016, 28, 5102-5109. [CrossRef]

56. Ravi, J.; Hills, A.E.; Cerasoli, E.; Rakowska, P.D.; Ryadnov, M.G. FTIR markers of methionine oxidation for early detection of oxidized protein therapeutics. Eur. Biophys. J. 2011, 40, 339-345. [CrossRef]

57. Modes, C.D.; Bhattacharya, K.; Warner, M. Gaussian curvature from flat elastica sheets. Proc. R. Soc. A Math. Phys. Eng. Sci. 2011, 467, 1121-1140. [CrossRef]

58. de Haan, L.T.; Sánchez-Somolinos, C.; Bastiaansen, C.M.W.; Schenning, A.P.H.J.; Broer, D.J. Engineering of complex order and the macroscopic deformation of liquid crystal polymer networks. Angew. Chem. Int. Ed. 2012, 51, 12469-12472. [CrossRef]

59. Warner, M. Topographic Mechanics and Applications of Liquid Crystalline Solids. Annu. Rev. Condens. Matter Phys. 2020, 11, 125-145. [CrossRef]

60. Sawa, Y.; Ye, F.; Urayama, K. Shape selection of twist-nematic-elastomer ribbons. Proc. Natl. Acad. Sci. USA 2011, 108, 6364-6368. [CrossRef]

(C) 2020 by the authors. Licensee MDPI, Basel, Switzerland. This article is an open access article distributed under the terms and conditions of the Creative Commons Attribution (CC BY) license (http://creativecommons.org/licenses/by/4.0/). 